\title{
МОРФОЛОГИЯ ПЕЧЕНИ КРЫС В УСЛОВИЯХ ОСТРОГО ЭМОЦИОНАЛЬНО-БОЛЕВОГО СТРЕССА НА ФОНЕ ВВЕДЕНИЯ ДЕЛЬТА-СОН ИНДУЦИРУЮЩЕГО ПЕПТИДА
}

\author{
(С Белых А.Е. ${ }^{1,3}$, Дудка В.Т. ${ }^{2}$, Бобынцев И.И. ${ }^{1,3}$, Крюков А.А. ${ }^{l}$ \\ ${ }^{1}$ Кафедра патофизиологии, ${ }^{2}$ кафедра патологической анатомии, \\ ${ }^{3}$ НИИ общей патологии Курского государственного медицинского университета, Курск \\ E-mail: bobig@mail.ru
}

\begin{abstract}
Острый эмоционально-болевой стресс по результатам морфометрического исследования печени вызывал уменьшение паренхиматозно-стромального соотношения за счет расширения и полнокровия кровеносных сосудов, застойных явлений в желчных капиллярах и холестаза, увеличение текущей интенсивности функционирования печени и развитие дегенеративных и деструктивных изменений в гепатоцитах, повышение текущей пролиферативной активности гепатоцитов со снижением глубины репаративных резервов. Дельта-сон индуцирующий пептид (ДСИП) у стрессированных животных во всех использованных дозах (40, 120 и 360 мкг/кг) повышал показатели паренхиматозностромального соотношения. Введение пептида в дозе 40 мкг/кг сопровождалось увеличением у стрессированных животных текущей интенсивности функционирования гепатоцитов и накоплением потенциальных репаративных резервов. В дозе 360 мкг/кг ДСИП способствовал уменьшению полнокровия, застойных явлений и холестаза, значительному снижению дегенеративных процессов и увеличению репаративных резервов печени. В условиях острого эмоционально-болевого стресса также снижалась относительная масса тимуса, что нивелировалось после введения ДСИП в дозах 40 и 360 мкг/кг. При этом как стресс, так и введение пептида не оказывали влияния на относительную массу печени.
\end{abstract}

Ключевые слова: печень, гепатоциты, дельта-сон индуцирующий пептид, ДСИП, стресс, морфометрия.

\section{RATS' LIVER MORPHOLOGY IN CONDITIONS OF ACUTE FOOT-SHOCK STRESS AGAINST THE BACKGROUND OF DELTA SLEEP-INDUCING PEPTIDE INJECTION Belykh A.E. ${ }^{1,3}$, Dudka V.T. ${ }^{2}$, Bobyntsev I.I. ${ }^{1,3}$, Kryukov A.A. ${ }^{l}$ \\ ${ }^{1}$ Department of Pathophysiology, ${ }^{2}$ Department of Pathological Anatomy, ${ }^{3}$ Research Institute of General Pathology of Kursk State Medical University, Kursk}

An acute foot-shock stress caused a reduction in parenchymal-stromal ratio due to the dilation and hyperemia of the liver blood vessels, a stagnation phenomenon in the bile capillaries and cholestasis, an increase in the intensity of the liver current functioning and development of degenerative and destructive changes in hepatocytes, an increase in the current proliferative activity of hepatocytes along with the reduced depth of reparative reserves according to the results of the morphometric examination of the liver. Delta sleep-inducing peptide (DSIP) in the every dose used (40, 120, and $360 \mathrm{mcg} / \mathrm{kg}$ ) increased the parenchymal-stromal ratio indicators in stressed animals. Peptide introduction in a dose of $40 \mathrm{mcg} / \mathrm{kg}$ was accompanied by increasing the current rate of functioning hepatocytes and accumulating the potential reparative reserves in stressed animals. DSIP in a dose of $360 \mathrm{mcg} / \mathrm{kg}$ contributed to a decrease in hyperemia, stagnation phenomenon and cholestasis, a significant reduction in degenerative processes and an increase in the liver reparative reserves. In conditions of the acute foot-shock stress the thymus relative weight was also reduced, but it was leveled after administrating DSIP in doses of 40 and $360 \mathrm{mcg} / \mathrm{kg}$. Thus both the stress and peptide administration had no effect on the relative liver weight.

Keywords: liver, hepatocytes, delta sleep-inducing peptide, DSIP, stress, morphometry.

Известно, что среди способных вызывать стрессорную реакцию организма раздражителей особое значение имеют стимулы и ситуации, провоцирующие эмоциональный стресс. Данный вид стресса запускается психогенными факторами различной природы за счет проявления выраженных эмоционально-психических реакций [8]. Достаточно часто эмоциональный стресс сочетается с болевым, что способствует усилению стрессорного воздействия. Развивающие при этом стрессиндуцированные сдвиги на различных уровнях организации организма разнообразны и зависят от многих обстоятельств. В частности печень, которой принадлежит уникальная роль в регуляции постоянства внутренней среды организма, обладает высокой чувствительностью к действию стрессорных раздражителей на организм [9, 20]. Так, в условиях стресса изменяется метаболизм печеночных ферментов, принадлежащих к семье цитохрома Р450 (СYР) [15], развиваются стеатоз и неалкогольная жировая болезнь печени, увеличивается содержание триглицеридов, общего холестерина, уровней ИЛ-6 и ФНО в печени [16], может запускаться апоптоз гепатоцитов за счет увеличения экспрессии Fas-рецепторов и усиления миграции натуральных киллеров в печень [12]. При этом нарушение функционального состояния печени в дальнейшем способно оказывать значительное негативное воздействие на весь организм [18].

Важно отметить, что последствия стрессорного воздействия во многом определяются не толь- 
ко его силой и продолжительностью, но и состоянием стресслимитирующих механизмов организма, ограничивающих деструктивные последствия стресса. К числу активных компонентов данных механизмов относится дельта-сон индуцирующий пептид (ДСИП), являющийся регуляторным пептидом с полифункциональным характером биологической активности. Так, известны анальгетические [7], стресс-лимитирующие [10, 19], нейромодулирующие $[1,4]$ и мембраностабилизирующие [11] эффекты ДСИП. При этом важно отметить, что пептид способствует замене и переводу стресс-реакции на более эффективные и экономичные адаптационные стратегии $[2,3]$.

На основании вышеизложенных данных целью работы стало установление влияния внутрибрюшинного введения дельта-сон индуцирующего пептида на морфологию печени при остром эмоционально-болевом стрессе.

\section{МАТЕРИАЛЫ И МЕТОДЫ ИССЛЕДОВАНИЯ}

Эксперименты выполнены на 50 крысах-самцах Вистар массой 310-340 г, разделенных на группы по 10 животных, которые содержались в стандартных условиях вивария со свободным доступом к воде и пище при 12-часовом световом режиме и контролируемой температуре $\left(22 \pm 2^{\circ} \mathrm{C}\right)$. Исследования проводили в промежуток времени с 9 до 14 часов.

Все исследования проводились с соблюдением принципов Хельсинкской декларации о гуманном отношении к животным и в соответствии с решением регионального этического комитета.

В работе использовали дельта-сон индуцирующий пептид, имеющий формулу $\left(\mathrm{NH}_{2}\right) \mathrm{Trp}-$ Ala-Gly-Gly-Asp-Ala-Ser-Gly-Glu(COOH), синтезированный в НИИ химии Санкт-Петербургского государственного университета. Пептид растворяли в физиологическом растворе и вводили внутрибрюшинно за 60 мин до начала каждого стрессорного воздействия в дозах 40, 120 и 360 мкг/кг массы тела. Контрольным животным вводили эквивалентные объемы физиологического раствора из расчета 1 мл на 1 кг массы тела. Интактные животные не получали стрессорного воздействия, на протяжении эксперимента им вводили объемы физиологического раствора, эквивалентные таковым у контрольных стрессированных крыс.

Острый эмоционально-болевой стресс создавали электрокожным раздражением лап попарно сгруппированных животных в камере с электрифицированным решетчатым полом. С помощью программируемого электростимулятора на пол камеры в течение 30 минут подавались импульсы тока силой 0,2-0,3 mА продолжительностью 5 секунд с межимпульсным интервалом 15 секунд $[14,17]$.

Животных выводили из эксперимента путем обескровливания под эфирным наркозом. При заборе органов осуществляли взвешивание печени и тимуса и с учетом массы животного вычисляли индексы относительной массы органа («печень/тело» и «тимус/тело»). Для этого рассчитывали отношение массы органа к массе тела соответствующего животного и умножали полученный результат на 1000.

После выведения животных из эксперимента для морфологического исследования атравматично забирали печень и вилочковую железу. Для фиксации кусочков изучаемых органов использовали формалин 10\% в фосфатном буфере, затем проводили заливку тканей в парафин, готовили гистологические срезы толщиной 6-7 мкм и окрашивали гематоксилином и эозином.

Морфологическое исследование гистологических препаратов проводили на микроскопе Nikon Eclipse Ci co штатной цифровой цветной камерой. Морфологическую оценку состояния печеночной ткани осуществляли на основе морфометрического исследования гистологических срезов [6]. При помощи калиброванной окулярной сетки определяли следующие показатели: число митозов (ЧМ), число двухъядерных клеток (ЧДК), число целых ядросодержащих клеток (ЧК) и число точек пересечения сетки (ЧСТ), не попадающих на срезы гепатоцитов и их ядер. По результатам этих измерений рассчитывали: показатель паренхиматозной плотности $($ ПП=1-ЧСТ/Nузл); показатель функциональной клеточной массы (ФКМ=(ЧК/Sceт)*ПП*100000), характеризующий паренхиматозно-стромальные отношения в единице объема ткани; показатель ядерной массы (ЯМ=(ЧК+ЧДК)/Sceт)*ПП*100000), отражающий ядерно-цитоплазматические отношения в единице объема ткани; индекс массы двухъядерных клеток

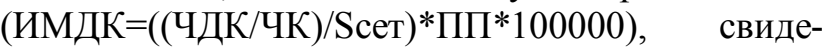
тельствующий о степени реализации восстановительных резервов единицы объема печеночной ткани; масс-митотический индекс (ММИ= ((ЧМ/ЧК)/Sceт)*ПП*100000), показывающий пролиферативную активность единицы объема печеночной ткани; показатель функционального кариоклеточного индекса (ФККИ=ЯМ/ФКМ), характеризующий количество ядерного материала в клетке в единице объема печеночной ткани; показатель средней площади среза гепатоцита $\left(\mathrm{C} \Pi C \Gamma=\left(\mathrm{S}_{\text {сет }} / Ч К\right) * П П\right), \quad$ пропорциональный $\quad$ его функциональной активности.

Характер распределения признаков в статистической выборке определяли с использованием критерия Шапиро-Уилка. Значимость полу- 
ченных результатов оценивали с помощью непарного параметрического t-критерия Стьюдента и непараметрического критерия Манна-Уитни в зависимости от типа распределения признаков. Ставанием программного пакета MS Excel и программной среды вычислений $\mathrm{R}[5,13]$. Результаты считали достоверными при $\mathrm{p}<0,05$.

\section{РЕЗУЛЬТАТЫ ИССЛЕДОВАНИЯ И ИХ ОБСУЖДЕНИЕ}

Как видно из таблицы 1 , острый эмоционально-болевой стресс вызывал существенные сдвиги большинства исследуемых показателей морфологического состояния печени. Так, паренхиматозная плотность достоверно уменьшалась на 19\% $22 \%(\mathrm{p}<0,01)$, что свидетельствует об уменьшении паренхиматозно-стромального соотношения (снижение «полезного» объема паренхимы) за счет расширения кровеносных сосудов и печеночных капилляров, наличии застойных явлений, полнокровия и холестаза по сравнению с интактными животными. У стрессированных животных также отмечалось снижение показателя ядерной массы на 21\% ( $<0,05)$, указывающее на дегенеративные и деструктивные процессы в печеночной ткани, гистологически представленные развитием в центролобулярных отделах долек преимущественно гиалиново-капельной дистрофии гепатоцитов, а в периферических отделах - гидропической дистрофии (рис. 3a, б). тистическую обработку проводили с использо$(\mathrm{p}<0,001)$, а функциональная клеточная масса - на

Кроме того, по сравнению с интактными животными у контрольной группы наблюдалось увеличение масс-митотического индекса на $67 \%$ $(\mathrm{p}<0,05)$, что свидетельствует об увеличении текущей интенсивности функционирования печени при снижении глубины репаративных процессов, а также, в совокупности с уменьшением показателя средней площади среза гепатоцита на 15\% $(\mathrm{p}<0,001),-$ о повышении пролиферативной активности гепатоцитов. Достоверных различий в показателях индекса массы двухъядерных клеток и функционального кариоклеточного индекса при этом не отмечалось (рис. 1, 2).

Дисперсионный анализ выявил достоверные различия между уровнями паренхиматозной плотности $(p<0,001)$, ядерной массы $(p<0,05)$, индекса массы двухъядерных клеток $(p<0,01)$, масс-митотического $(\mathrm{p}<0,05)$ и функционального кариоклеточного индексов $(\mathrm{p}<0,001)$, средней площади среза гепатоцита $(\mathrm{p}<0,0001)$ при сравнении между собой результатов стрессированных крыс контрольной и опытных групп, однако достоверных изменений в уровнях функциональной клеточной массы $(p>0,05)$ при этом выявлено не было.

Введение пептида во всех использованных дозах вызывало увеличение паренхиматозностромального соотношения (повышение функционального объема паренхимы печени) по сравнению с контрольными животными, о чем свидетельствовало повышение показателя паренхиматозной плотности на $15 \%(\mathrm{p}<0,001), 8 \%$ $(\mathrm{p}<0,01)$ и $12 \%(\mathrm{p}<0,01)$ при введении ДСИП в дозах 40, 120 и 360 мкг/кг соответственно.

Таблица 1

Влияние ДСИП на показатели восстановительных процессов печени и относительную массу органов при остром эмоционально-болевом стрессе $(\mathrm{M} \pm \mathrm{m})$

\begin{tabular}{|l|c|c|c|c|c|}
\hline \multirow{2}{*}{ Группа } & \multirow{2}{*}{$\begin{array}{c}\text { Интактные } \\
\text { Показатель }\end{array}$} & \multirow{2}{*}{ животные } & \multirow{2}{*}{ Контроль } & \multicolumn{3}{|c|}{ Действие стресса } \\
\cline { 4 - 6 } & & & 40 мкг/кг & 120 мкг/кг & 360 мкг/кг \\
\hline ФКМ & $134,7 \pm 7,5$ & $104,5 \pm 5,9^{1}$ & $110,0 \pm 5,6$ & $115,3 \pm 3,8$ & $123,5 \pm 6,3^{*}$ \\
\hline ЯМ & $150,7 \pm 9,4$ & $119,5 \pm 7,9^{1}$ & $127,9 \pm 6,8$ & $133,2 \pm 5,1$ & $148,3 \pm 8,6^{*}$ \\
\hline ИМДК & $0,23 \pm 0,02$ & $0,22 \pm 0,03$ & $0,29 \pm 0,02^{*}$ & $0,26 \pm 0,02$ & $0,35 \pm 0,03^{*}$ \\
\hline ММИ & $0,007 \pm 0,001$ & $0,012 \pm 0,001^{1}$ & $0,016 \pm 0,001^{*}$ & $0,012 \pm 0,001$ & $0,012 \pm 0,001$ \\
\hline ПП & $0,61 \pm 0,02$ & $0,50 \pm 0,01^{1}$ & $0,57 \pm 0,01^{*}$ & $0,54 \pm 0,01^{*}$ & $0,56 \pm 0,01^{*}$ \\
\hline ФККИ & $1,12 \pm 0,01$ & $1,14 \pm 0,01$ & $1,16 \pm 0,01$ & $1,15 \pm 0,01$ & $1,20 \pm 0,01^{*}$ \\
\hline СПСГ & $280,0 \pm 8,7$ & $237,4 \pm 5,1^{1}$ & $296,8 \pm 7,5^{*}$ & $252,3 \pm 6,1$ & $253,0 \pm 10,9$ \\
\hline $\begin{array}{l}\text { Индекс } \\
\text { "Печень/тело" }\end{array}$ & $36,8 \pm 1,3$ & $35,8 \pm 1,1$ & $37,2 \pm 1,1$ & $38,2 \pm 1,1$ & $35,9 \pm 1,0$ \\
\hline $\begin{array}{l}\text { Индекс } \\
\text { "Тимус/тело" }\end{array}$ & $2,01 \pm 0,10$ & $1,68 \pm 0,05^{1}$ & $2,04 \pm 0,16^{*}$ & $1,72 \pm 0,08$ & $1,94 \pm 0,12^{*}$ \\
\hline
\end{tabular}

Примечание: * - p $<0,05-0,001$ по сравнению с контрольной группой крыс, подвергавшихся стрессу; ${ }^{1}$ - p<0,05-0,001 по сравнению с интактной группой крыс, не подвергавшихся стрессу. 


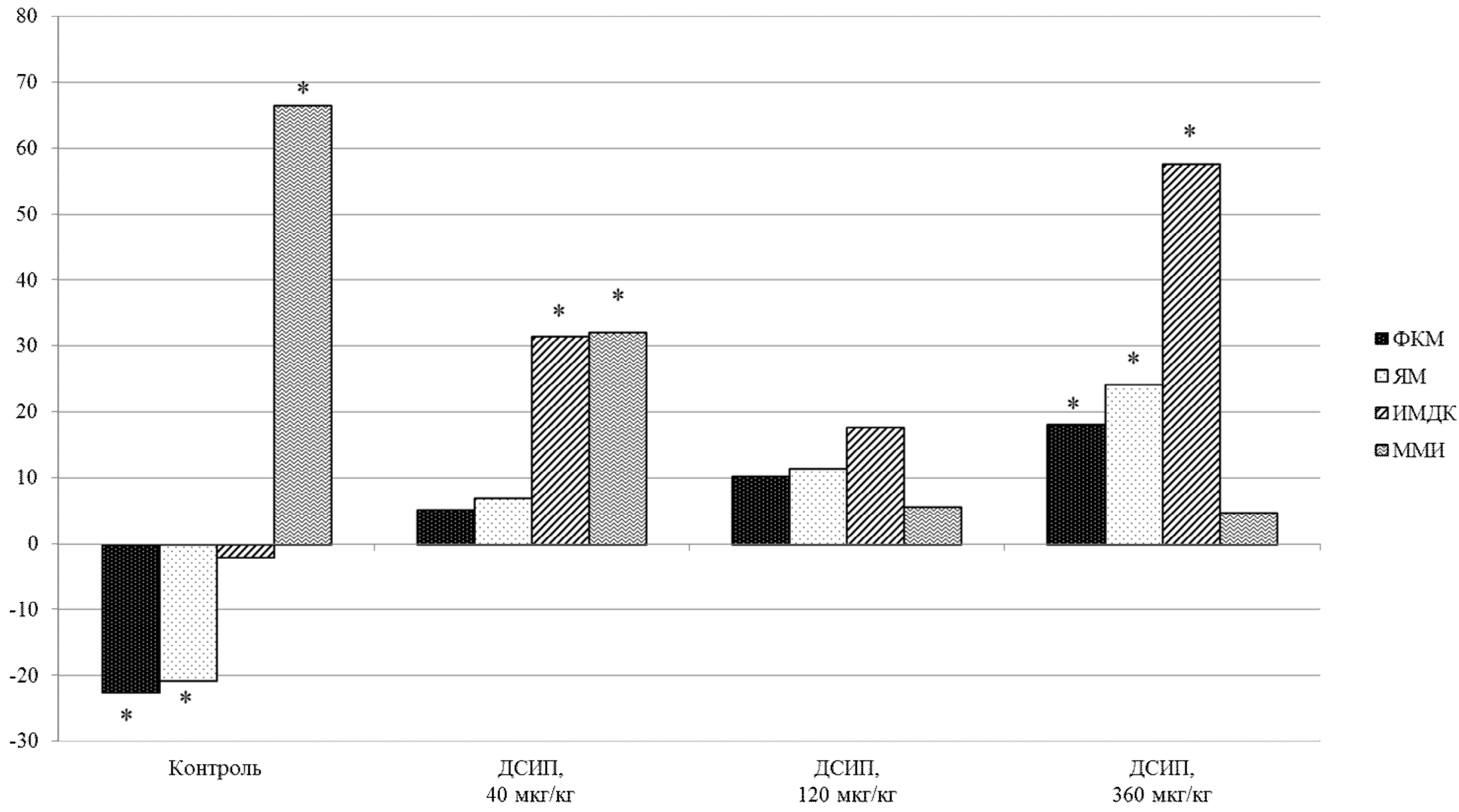

Рис. 1. Морфометрические показатели печени у животных различных групп в условиях острого эмоционально-болевого стресса.

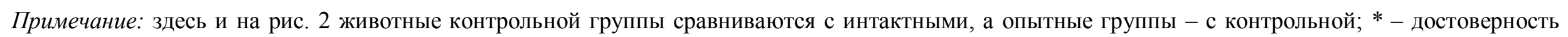
полученных результатов - $<<0,05-0,001$. 


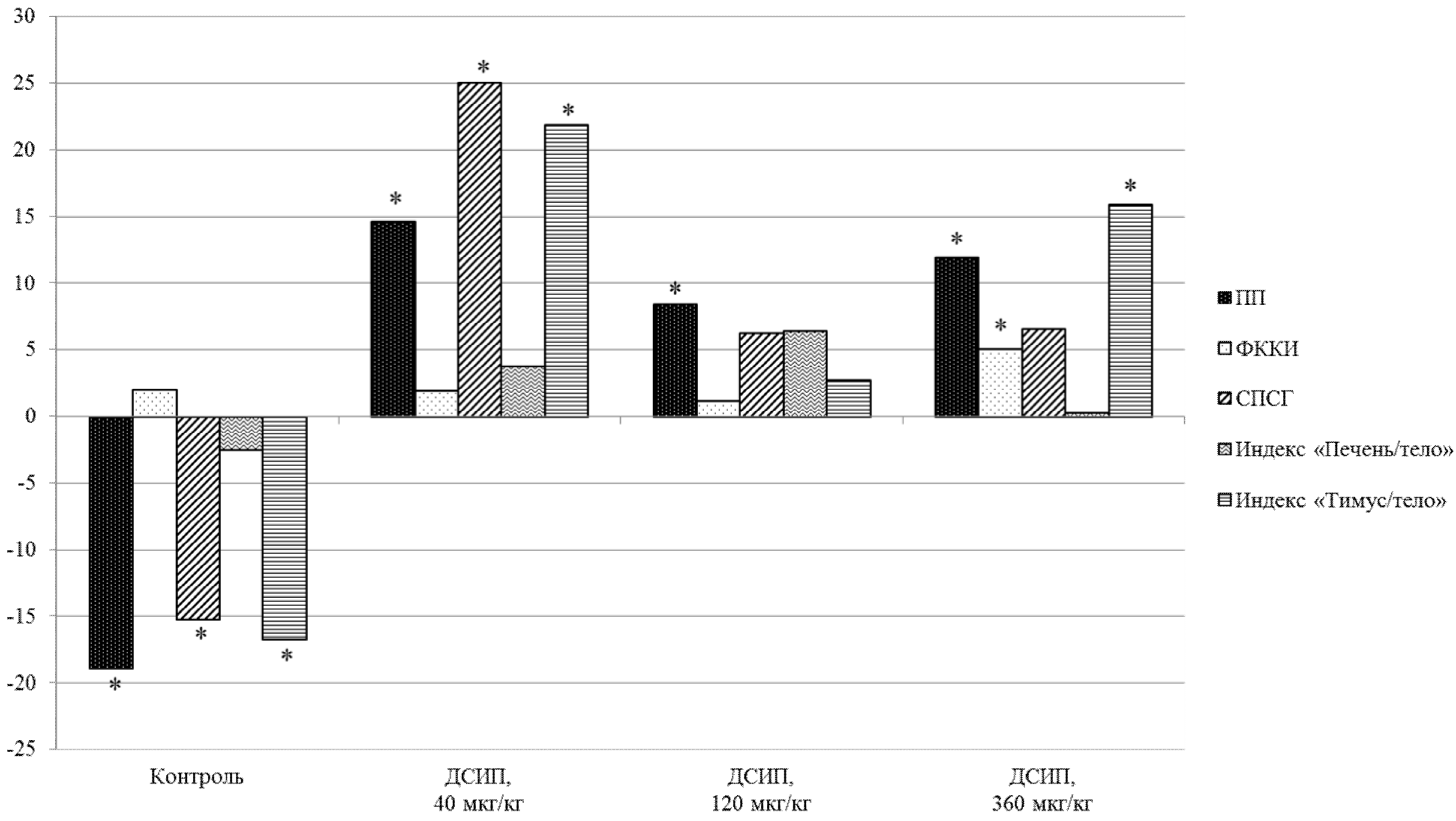

Рис. 2. Морфометрические показатели печени у животных различных групп в условиях острого эмоционально-болевого стресса. 


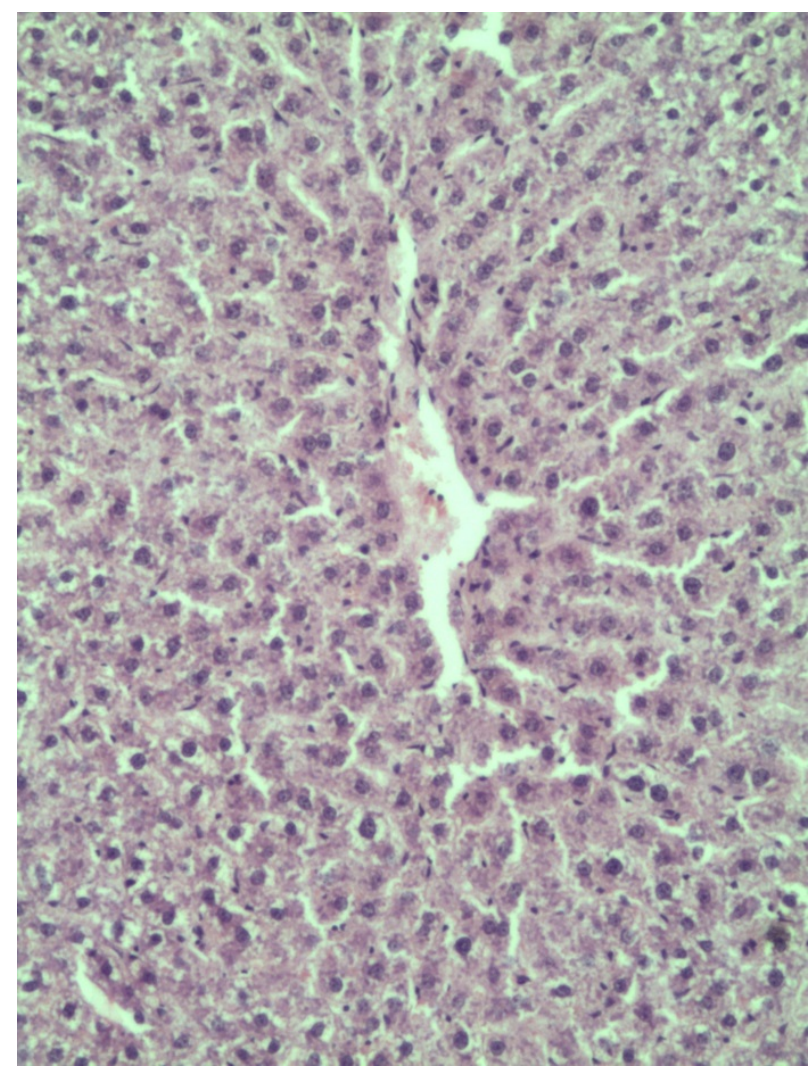

a

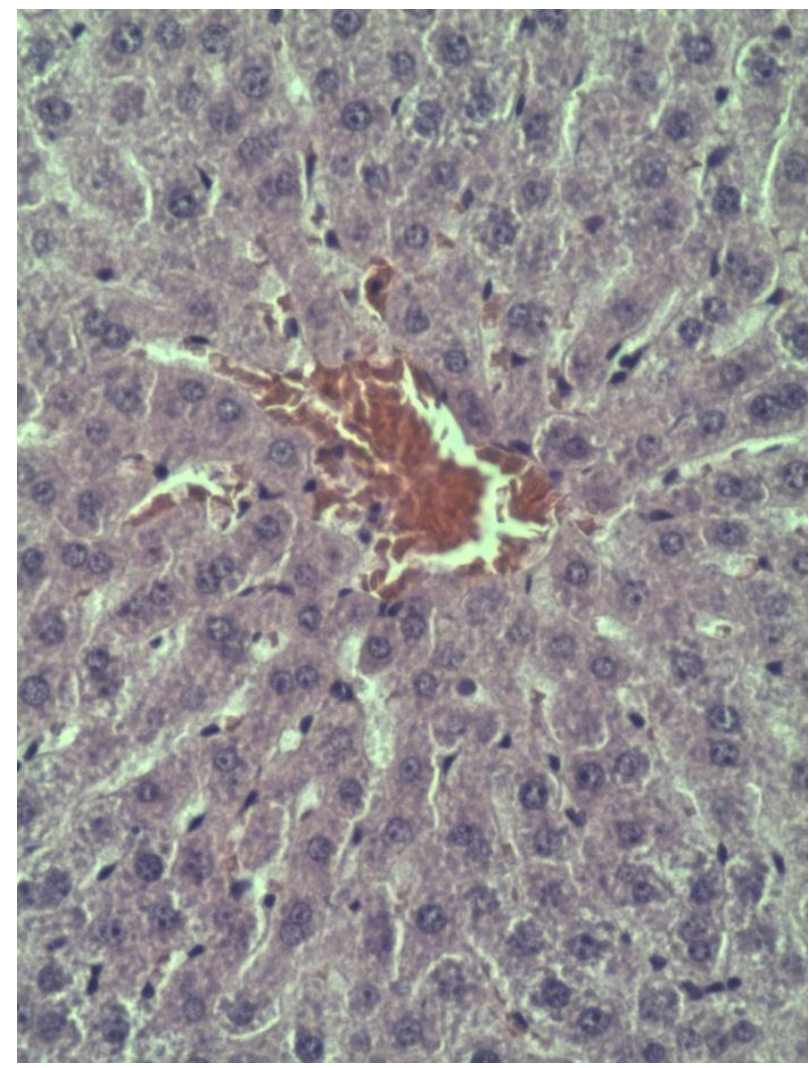

B

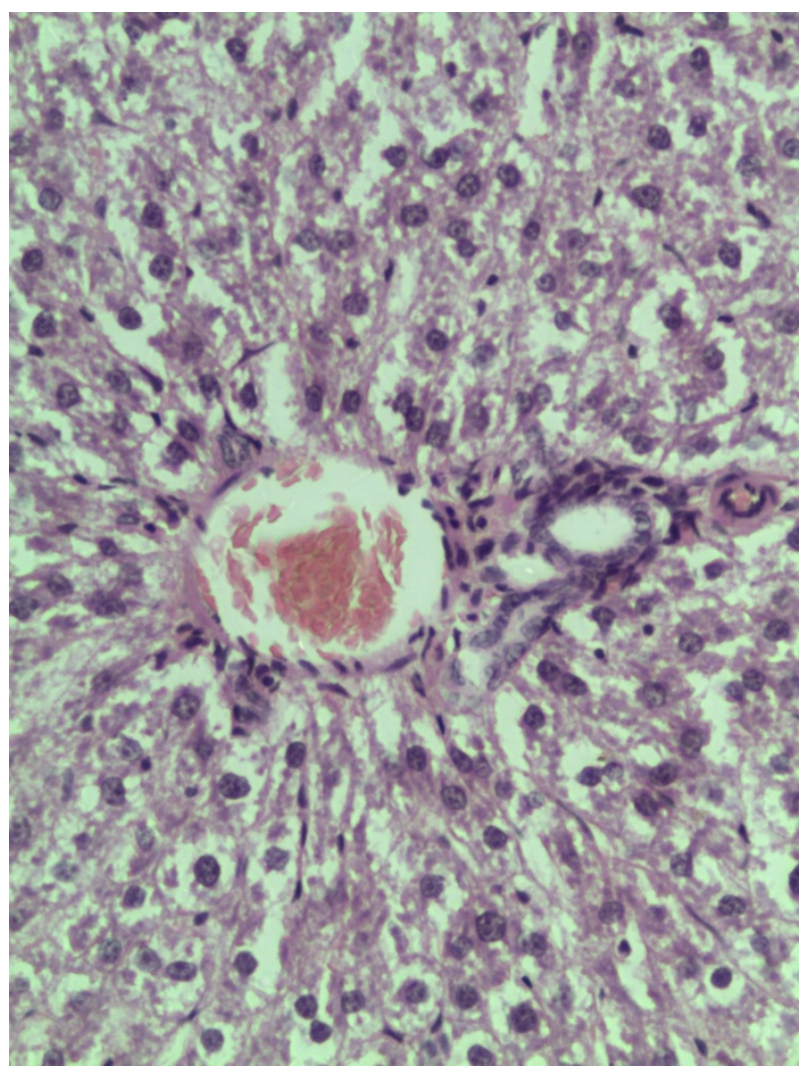

6

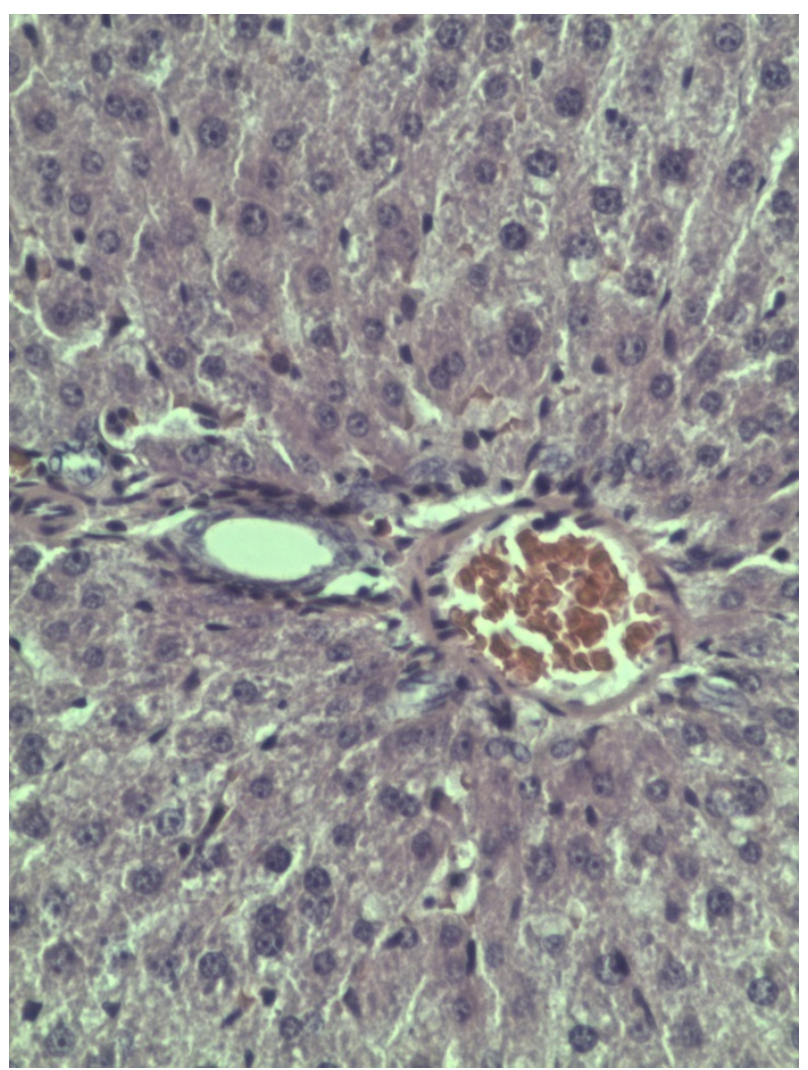

$\Gamma$

Рис. 3. Морфология печени у крыс при остром эмоционально-болевом стрессе (а - центролобулярно преимущественно гиалиново-капельная дистрофия гепатоцитов, б - в перипортальных отделах долек гидропическая дистрофия) и при остром эмоционально-болевом стрессе на фоне введения ДСИП в дозе 360 мкг/кг (в - в центролобулярных отделах гепатоциты без изменений, г - в периферических - слабо выраженная гиалиново-капельная дистрофия гепатоцитов). Окраска гематоксилин-эозином. Увеличение $\mathrm{a}-\mathrm{x} 100$; б-г - х200. 
В дозе 360 мкг/кг пептид вызвал возрастание сниженного под действием стресса уровня функциональной клеточной массы на $18 \%$ $(\mathrm{p}<0,05)$, что может говорить об уменьшении полнокровия, застойных явлений и холестаза. Кроме того, ДСИП в данной концентрации увеличивал показатель ядерной массы на 24\% $(\mathrm{p}<0,05)$, что свидетельствует о значительном снижение дегенеративных и деструктивных процессов в печени по сравнению с контрольными животными. При этом гистологически гистоархитектоника ткани печени сохранена, балочная структура четкая, синусоиды не расширены, в центролобулярных отделах гепатоциты без изменений, а в периферических отделах долек обнаруживается слабо выраженная гиалиново-капельная дистрофия гепатоцитов (рис. 3в, г).

Введение ДСИП в дозе 40 мкг/кг сопровождалось еще большим возрастанием масс-митотического индекса $(\mathrm{p}<0,05)$, (на $32 \%$, $\mathrm{p}<0,05)$, что позволяет предполагать увеличение относительно кратковременной интенсивности функционирования гепатоцитов и снижение глубины репаративных резервов ткани печени по сравнению с контролем. Однако, несмотря на данные сдвиги, нивелирование пептидом стрессиндуцированного снижения средней площади среза гепатоцита за счет её повышения на $25 \%(\mathrm{p}<0,001)$ в сочетании с увеличением индекса массы двухъядерных клеток (на $32 \%$, $\mathrm{p}<0,05)$ свидетельствует об общем расширении объема репаративных резервов печени. Повышение индекса массы двухъядерных клеток (на $58 \%, \mathrm{p}<0,01)$ отмечалось также и при использовании дозы 360 мкг/кг.

В условиях острого эмоционально-болевого стресса в группе контрольных крыс также снижалась на $17 \%(\mathrm{p}<0,05)$ относительная масса тимуса (табл. 1, рис. 2). В подопытных группах в данных условиях эксперимента введение ДСИП в дозах 40 и 360 мкг/кг вызывало увеличение данного показателя соответственно на 22\% $(p<0,05)$ и $16 \% \quad(p<0,05)$. При этом следует отметить, что как стресс, так и введение пептида не оказывало влияния на относительную массу печени. Дисперсионный анализ не выявил достоверных отличий в уровнях относительной массы печени, но позволил установить их при сравнении относительных масс тимуса между исследуемыми группами $(\mathrm{p}<0,05)$.

На основании полученных данных можно заключить, что стрессорное воздействие вызывало уменьшение паренхиматозностромального соотношения за счет расширения и полнокровия кровеносных сосудов, застойных явлений в желчных капиллярах и холестаза, увеличение текущей интенсивности функционирования печени и развитие дегенеративных и деструктивных изменений в гепатоцитах, повышение текущей пролиферативной активности гепатоцитов со снижением глубины репаративных резервов. ДСИП в условиях стресса во всех использованных дозах повышал показатели паренхиматозно-стромального соотношения. Введение ДСИП в наименьшей использованной дозе 40 мкг/кг сопровождалось увеличением у стрессированных животных текущей интенсивности функционирования гепатоцитов и накоплением потенциальных репаративных резервов. В наибольшей дозе 360 мкг/кг пептид способствовал уменьшению полнокровия, застойных явлений и холестаза, значительному снижению дегенеративных процессов и увеличению репаративных резервов печени. В условиях острого эмоционально-болевого стресса также снижалась относительная масса тимуса, что нивелировалось после введения ДСИП в дозах 40 и 360 мкг/кг. При этом как стресс, так и введение пептида не оказывали влияния на относительную массу печени.

При анализе полученных данных также необходимо отметить, что указанные морфологические изменения в печени развивались после достаточно короткого однократного эмоционально-болевого стрессорного воздействия. Данный факт может свидетельствовать о значительной вовлеченности печени и ее резервов в реализацию стрессорной реакции как вследствие активации метаболических процессов в организме, так и за счет воздействия на нее стрессиндуцированных повреждающих механизмов. При этом наблюдавшееся после введения стрессированным животным ДСИП влияние на исследуемые показатели морфологического состояния печени было направлено на ограничение повреждающего действия стресса на печень, т.е. имело стресслимитирующий характер. В пользу стресслимитирующего действия пептида свидетельствует и нивелирование после использования вызванного стрессом снижения массы тимуса.

Таким образом, острый эмоциональноболевой стресс вызывал у крыс морфологические изменения в печени, которые корригировались за счет стресслимитирующих гепатопротекторных эффектов ДСИП.

\section{ЛИТЕРАТУРА}

1. Белякова Е.И., Колмакова Т.С. Влияние пептида дельта-сна на моноаминергические системы мозга крыс в начальный период ноцицептивного 
воздействия // Нейрохимия. - 2007. - Т. 24, № 2. C. $156-160$.

2. Доведова Е.Л., Ещеенко Н.Д. Действие дельта-сон индуцирующего пептида на метаболизм моноаминов при экспериментальной эпилепсии // Вестник СПбГУ. Серия 3: Биология. - 2011. № 2. - С. 68-74.

3. Льссенко А.В., Альперович Д.В., Ускова Н.И., Менджериикая Л.Г., Михалева И.И. Сравнительное изучение эффективности применения дельта-сон-индуцирующего пептида для коррекции функционально-метаболических сдвигов в условиях гипоксии и физической нагрузки // Нейрохимия. - 1999. - Т. 16, № 1. C. 37-44.

4. Льсенко А.В., Менджериикий А.М. Свойства и механизмы реализации эффектов пептида, индуцирующего дельта-сон // Успехи совр. биологии. - 1995. - Т. 115, вып. 6. - С. 729-739.

5. Мастицкий С.Э., Шитиков В.К. Статистический анализ и визуализация данных с помощью $\mathrm{R}$. Черно-белое издание. - М. : Изд-во «ДМК Пресс», 2015. -496 c.

6. Способ оценки восстановительных процессов печени: пат. 2308031 Рос. Федерация : МПК G01N 33/48, A61B 10/00 / Е.B. Антопольская, И.А. Швейнов, А.И. Конопля, А.В. Ушкалов; патентообладатель: Курск. гос. мед. универ. № 2005141259/14; заявл. 28.12.2005; опубл. 10.10 .2007 , Бюл. № 28 . -6 c.

7. Стрекалова T.B. Дельта-сон индуцирующий пептид (ДСИП): проблемы эндогенного происхождения и биологической активности // Нейрохимия. - 1998. - Т. 15, № 3. - С. 227-238.

8. Хныченко Л.К., Сапронов Н.С. Стресс и его роль в развитии патологических процессов // Обзоры по клин. фармакол. и лек. терапии. - 2003. - Т. 2, № 3. - C. 2-15.

9. Arias I.M., Alter H.J., Boyer J.L., Cohen D.E., Fausto N., Shafritz D.A., Wolkoff A.W. The Liver: Biology and Pathobiology: Fifth Edition. - Chichester, UK ; Hoboken, NJ : Wiley-Blackwell, 2009. - 1191 p. doi: 10.1002/9780470747919.

10. Bogolepov N.N., Popova E.N., Koplik E.V., Krivitskaya G.N., Sudakov K.V. Structural-functional organization of neurons in the cerebral cortex of rats with different levels of resistance to emotional stress in conditions of exposure to delta sleep-inducing peptide // Neurosci Behav Physiol. - 2004. - Vol. 34, N 6. - P. 611-616.

11. Bondarenko T.I., Milyutina N.P., Shustanova T.A., Mikhaleva I.I. The effects of delta sleep-inducing peptide on the intensity of lipid peroxidation and xanthine oxidase activity in rat tissues during cold stress // Neurosci Behav Physiol. - 2001. - Vol. 31, N 1. - P. 83-86.

12. Chida Y., Sudo N., Sonoda J., Sogawa H., Kubo C. Electric foot shock stress-induced exacerbation of alpha-galactosylceramide-triggered apoptosis in mouse liver. // Hepatology. - 2004. - Vol. 39, N 4. P. 1131-1140.

13. Crawley M.J. The R Book, 2nd Edition. - New Jersey : John Wiley \& Sons Ltd., 2012 - 1076 p.

14. Hranilovic D., Bucan M., Wang Y. Emotional response in dopamine D2L receptor-deficient mice // Behav Brain Res. - 2008. - Vol. 195, N 2. - P. 246-250. doi: 10.1016/j.bbr.2008.09.007.

15. Konstandi $M$. Psychophysiological stress: a significant parameter in drug pharmacokinetics // Expert Opin Drug Metab Toxicol. - 2013. - Vol. 9, N 10. P. 1317-1334. - doi: 10.1517/17425255.2013.816283. Epub 2013 Jul 9.

16. Liu Y.Z., Chen J.K., Zhang Y., Wang X., Qu S., Jiang C.L. Chronic stress induces steatohepatitis while decreases visceral fat mass in mice. // BMC Gastroenterol. - 2014. - Vol. 14. - P. 106. - doi: 10.1186/1471-230X-14-106.

17. Matthews D.B., Morrow A.L., O'Buckley T., Flanigan T.J., Berry R.B., Cook M.N., Mittleman G., Goldowitz D., Tokunaga S., Silvers J.M. Acute mild footshock alters ethanol drinking and plasma corticosterone levels in C57BL / 6J male mice, but not DBA/2J or A/J male mice. // Alcohol. - 2008. - Vol. 42, N 6. P. 469-476. - doi: 10.1016/j.alcohol.2008.05.001.

18. Park B.J., Lee Y.J., Lee H.R. Chronic liver inflammation: Clinical implications beyond alcoholic liver disease // World J Gastroenterol. - 2014. Vol. 20, N 9. - P. 2168-2175.

19. Pollard B.J., Pomfrett C.J. Delta sleep-inducing peptide // Eur J Anaesthesiol. - 2001. - Vol. 18, N 7. - P. 419-422.

20. Sánchez-Valle V., Chávez-Tapia N.C., Uribe M., Méndez-Sánchez $N$. Role of oxidative stress and molecular changes in liver fibrosis: a review // Curr Med Chem. - 2012. - Vol. 19, N 28. - P. 4850-4860. 